IAF-93- R. 1.426

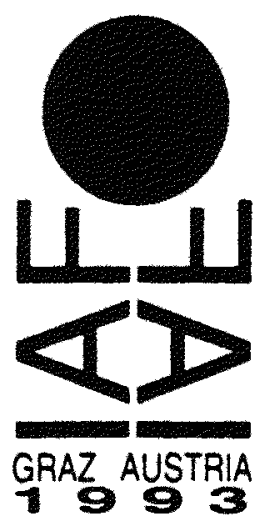

\title{
INTEGRATION OF RADIOISOTOPE HEAT SOURCE WITH STIRLING ENGINE AND COOLER FOR VENUS INTERNAL-STRUCTURE MISSION
}

\author{
A. Schock
}

Fairchild Space and Defense Corporation 20301 Century Boulevard

Germantown, Maryland 20874

United States of America

\section{4th CONGRESS OF THE INTERNATIONAL ASTRONAUTICAL FEDERATION October 16-22, 1993 / Graz, Austria}




\section{DISCLAIMER}

This report was prepared as an account of work sponsored by an agency of the United States Government. Neither the United States Government nor any agency Thereof, nor any of their employees, makes any warranty, express or implied, or assumes any legal liability or responsibility for the accuracy, completeness, or usefulness of any information, apparatus, product, or process disclosed, or represents that its use would not infringe privately owned rights. Reference herein to any specific commercial product, process, or service by trade name, trademark, manufacturer, or otherwise does not necessarily constitute or imply its endorsement, recommendation, or favoring by the United States Government or any agency thereof. The views and opinions of authors expressed herein do not necessarily state or reflect those of the United States Government or any agency thereof. 


\section{DISCLAIMER}

Portions of this document may be illegible in electronic image products. Images are produced from the best available original document. 


\title{
INTEGRATION OF RADIOISOTOPE HEAT SOURCE WITH STIRLING ENGINE AND COOLER FOR VENUS INTERNAL-STRUCTURE MISSION
}

\author{
Alfred Schock \\ Fairchild Space and Defense Corporation \\ 20301 Century Blvd. \\ Germantown, MD 20874 \\ (301) 428-6272
}

\begin{abstract}
$\underline{\text { Abstract }}$
The primary mission goal is to perform longterm seismic measurements on Venus, to study its largely unknown internal structure. The principal problem is that most payload components cannot long survive Venus's harsh environment, 90 bars at $500^{\circ} \mathrm{C}$. To meet the mission life goal, such components must be protected by a refrigerated payload bay.

JPL investigators have proposed a mission concept employing a lander with a spherical payload bay cooled to $25^{\circ} \mathrm{C}$ by a Stirling cooler powered by a radioisotope-heated Stirling engine. To support JPL's mission study, NASA/Lewis and MTI have proposed a conceptual design for a hydraulically coupled Stirling engine and cooler, and Fairchild Space with support of the Department of Energy - has proposed a design and integration scheme for a suitable radioisotope heat source.

The key integration problem is to devise a simple, light-weight, and reliable scheme for forcing the radioisotope decay heat to flow through the Stirling engine during operation on Venus, but to reject that heat to the external environment when the Stirling engine and cooler are not operating (e.g., during the cruise phase, when the landers are surrounded by heat shields needed for protection during subsequent entry into the Venusian atmosphere.) A design and integration scheme for achieving these goals, together with results of detailed thermal analyses, are described in this paper.
\end{abstract}

\section{INTRODUCTION}

Ellen R. Stofan and R. Stephen Saunders of the Jet Propulsion Laboratory have come up with the concept of the Venus Internal Structure Mission (VISM) [1] in which three identical spacecraft are landed on Venus to study its internal structure by means of seismic measurements for a period of at least four months. According to these investigators, the detailed structure of the Venus interior is one of the key remaining questions about that planet, and seismic measurements would allow development of a quantitative three-dimensional model of its interior, which is of great scientific interest.

To further explore the feasibility of such a mission, a study team was formed at JPL under the leadership of Kerry Nock. The principal feasibility problem is the high temperature $\left(-500^{\circ} \mathrm{C}\right)$ and high atmospheric pressure $(90 \mathrm{bar})$ of the Venusian environment. Some payload components (seismometer, antenna, $\mathrm{Na} / \mathrm{S}$ battery) can tolerate such temperatures, but most electronic components can only endure them for brief periods.

The JPL study team concluded that long-term operation on the Venus surface with current electronics would only be possible if the sensitive payload were placed in a refrigerated bay maintained at room temperature $\left(-25^{\circ} \mathrm{C}\right)$. They postulated a spherical payload bay of $38 \mathrm{~cm}$ diameter, and concluded that the VISM landers need very little electrical power but alot of 
cooling power, which could best be met by a Stirling refrigerator powered by a pneumatically coupled Stirling engine.

They then turned to NASA's Lewis Research Center (LeRC) which had been sponsoring the development of free-piston Stirling engines at MTI (Mechanical Technologies, Inc.) for many years. In fact, MTI recently tested a 12-kw(e) free-piston Stirling engine coupled to a linear alternator. Its performance showed excellent agreement with analytical predictions, yielding an output of $12 \mathrm{kw}(\mathrm{e})$ at an overall efficiency of $23 \%$. In the present application there is no need for a linear alternator, since most of the required output is in the form of mechanical power, to be pneumatically transmitted to the Stirling refrigerator or cooler.

To meet JPL's cooling goal, MTI and LeRC proposed the Stirling cooler design depicted in Figure 1, powered by the opposed-piston Stirling engine pictured in Figure 2.

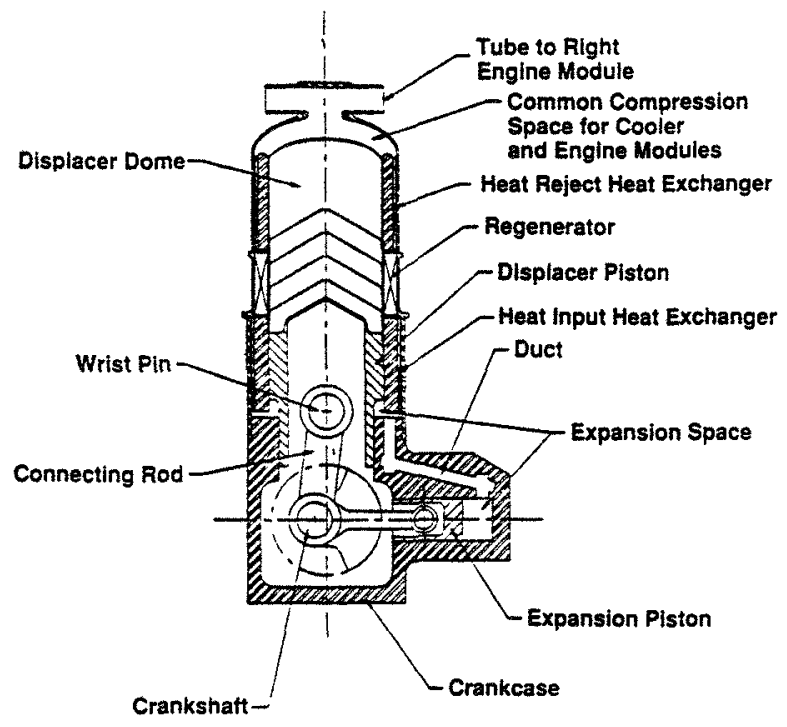

Fig.1 Stirling Cooler

The two units use a common working fluid (helium at 90 bars) which also acts as the mechanical coupling between them. Their respective heat input temperatures are $275^{\circ} \mathrm{K}$ and $1450^{\circ} \mathrm{K}$, and their common heat rejection temperature is $770^{\circ} \mathrm{K}$. The detailed design parameters and the design rationale will be described in a separate MTI report. Their analyses predicted a Coefficient of Performance of 0.37 for the cooler and a thermal-tomechanical energy conversion efficiency of $31 \%$ for the engine. They concluded that a thermal input of 1950 watts to the engine is required to yield the cooling rate specified by JPL.

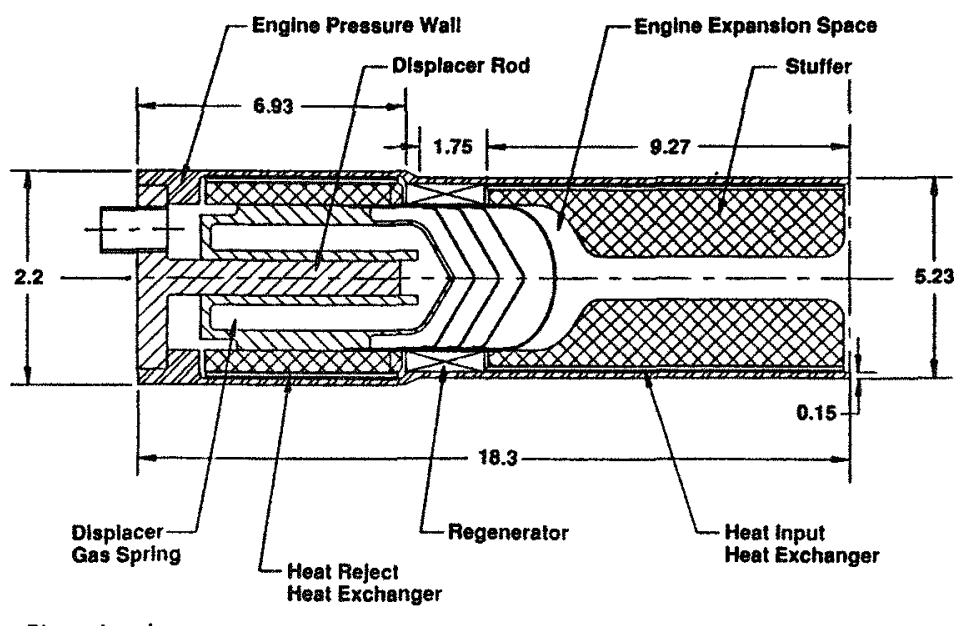

Dimensions in $\mathrm{cm}$

Fig.2 Stirling Engine (One Half)

At that point, LeRC and MTI asked Fairchild Space and Defense Corporation, under contract to the U.S. Department of Energy's Office of Special Applications, to prepare a system design integrating a radioisotope heat source with the Stirling engine and with the spacecraft.

\section{INTEGRATED SYSTEM DESIGN}

The Stirling engine is powered by a radioisotope heat source. The heat source's basic building block is the GPHS (General Purpose Heat Source) module depicted in Figure 3. This 250 -watt(t) module was developed by the Department of Energy for a broad range of space applications. The modules have exhibited great reliability and durability, and have been subjected to very extensive safety analyses and tests for all plausible accident modes. They were successfully used on NASA's Galileo and ESA's Ulysses missions, and are currently in production for use on NASA's upcoming Cassini mission. As seen, each module contains four 62.5-watt(e) iridium-clad ${ }^{238} \mathrm{PuO}_{2}$ pellets, in addition to various graphite components that serve as passive safety provisions, to preserve the integrity of the clads under all plausible accident modes [2]. 


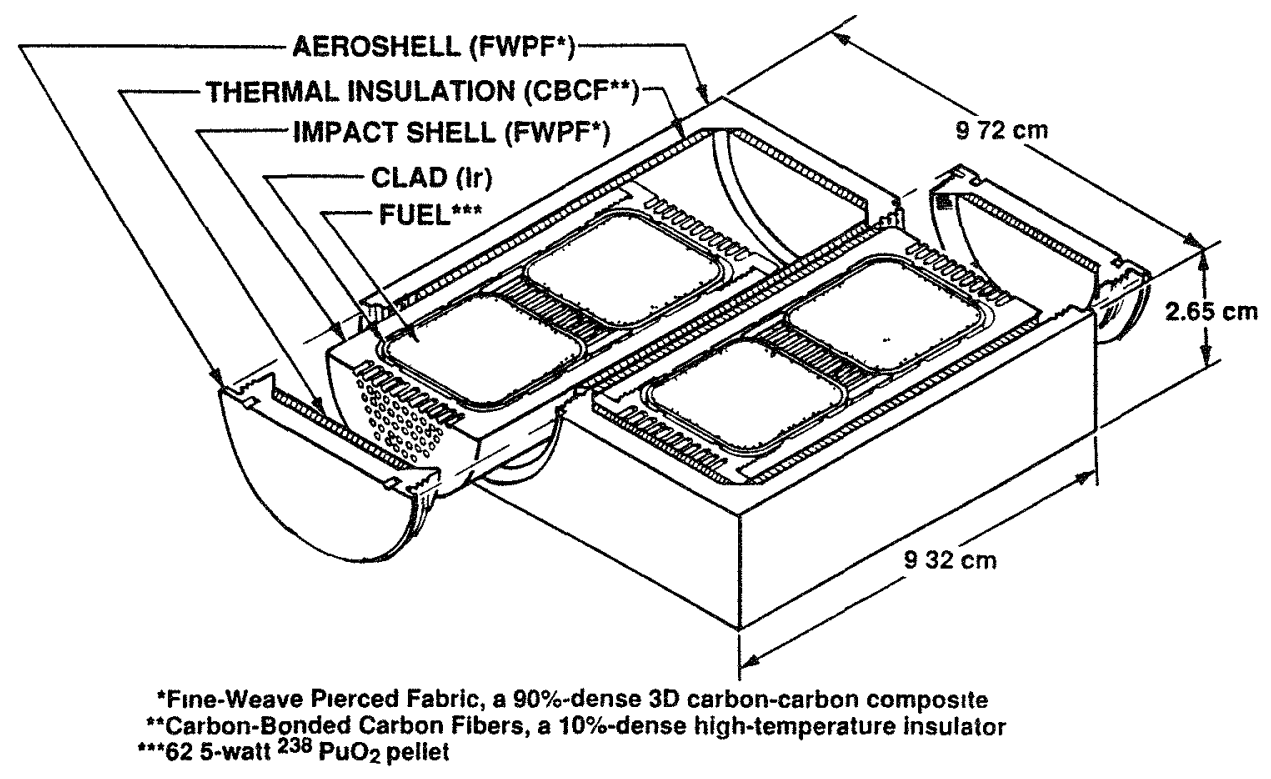

Fig.3 GPHS-General Purpose Heat Source Module (250 Thermal Watt) Sectioned at Mid-Plane

The engine is powered by eight heat source modules, arranged as shown in Figure 4 The dimensions of the $2 \mathrm{kw}(\mathrm{t})$ heat source stack are displayed in Figure 5 As seen, the modules form a square hole which accommodates the engine's cylindrical heater head

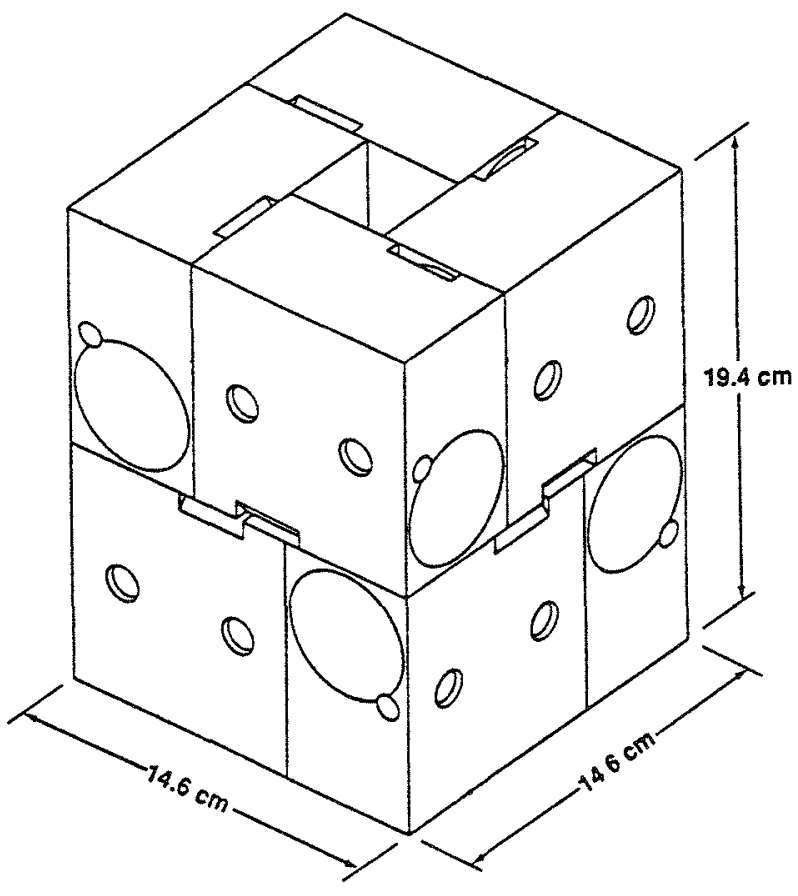

Fig.5 Heat Source Stack

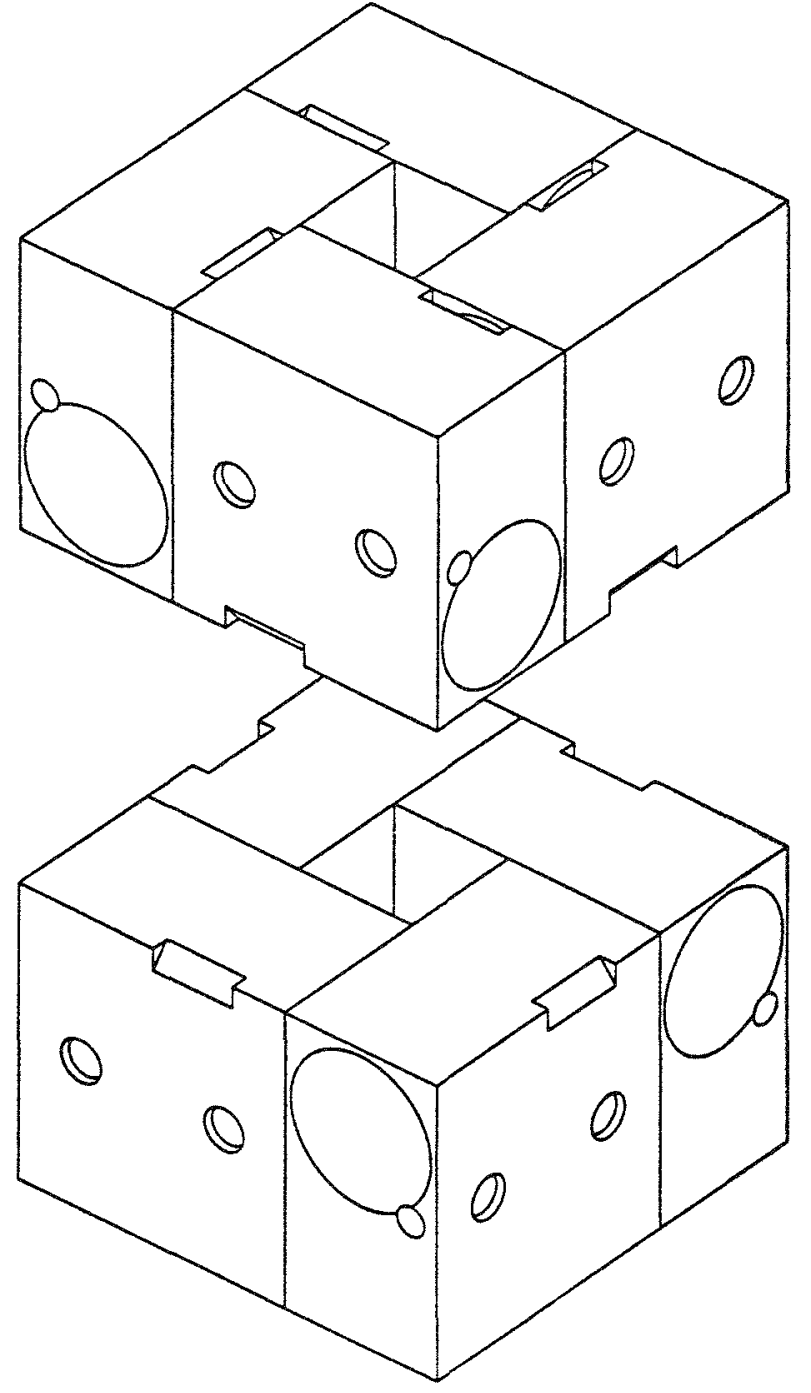

Fig.4 Arrangement of 8 GPHS Modules (2 kwt) 
Integration of the heat source with the engine must satisfy a number of conflicting requirements. During engine operation on Venus, the outside of the heat source must be well insulated so that most of the heat flows to the engine and relatively little is lost to the outside. When the engine is not operating (such as during cruise, when cooling of the electronics bay is not required), the external insulation must be spoiled so as to dump the heat to the outside and prevent overheating of the heat source.

An arrangement for achieving these and other objectives is depicted in Figure 6, which shows a cross-section normal to the engine axis. As can be seen, the heat source stack is surrounded by two square cans: an inner thinwalled iridium heat source can, and an outer 0.63 $\mathrm{cm}$-thick titanium pressure can with five external stiffeners. The $0.63-\mathrm{cm}$ gap between the two cans contains 60 to 120 layers of $0.00075 \mathrm{~cm}$ thick molybdenum foil. Similar multifoil packages are used in RTGs. They provide excellent thermal insulation in vacuum, but very poor insulation in helium. Therefore, the gap between the two cans will be flooded with $\sim 1$ bar of helium before launch and remain so during cruise, and will be evacuated before engine startup, shortly before arrival at Venus. As will be seen, this results in very benign temperatures during ground storage and during cruise.

In addition, the design requires a provision for venting the helium generated by the fuel's alpha decay, to prevent excess pressure and failure of the heat source can. A gas management scheme for continuously venting the heat source chamber and for evacuating the insulation chamber is depicted in Figure 7, which shows the engine and heat source assembly, cross-sectioned parallel to the engine axis. The scheme assumes that the helium produced by alpha decay is vented directly into the lowtemperature electronics bay. Only a thin capillary tube is required to vent this helium, which is generated at the rate of 327 standard cc per year per heat source module. Because of the electronic bay's relatively large volume, this

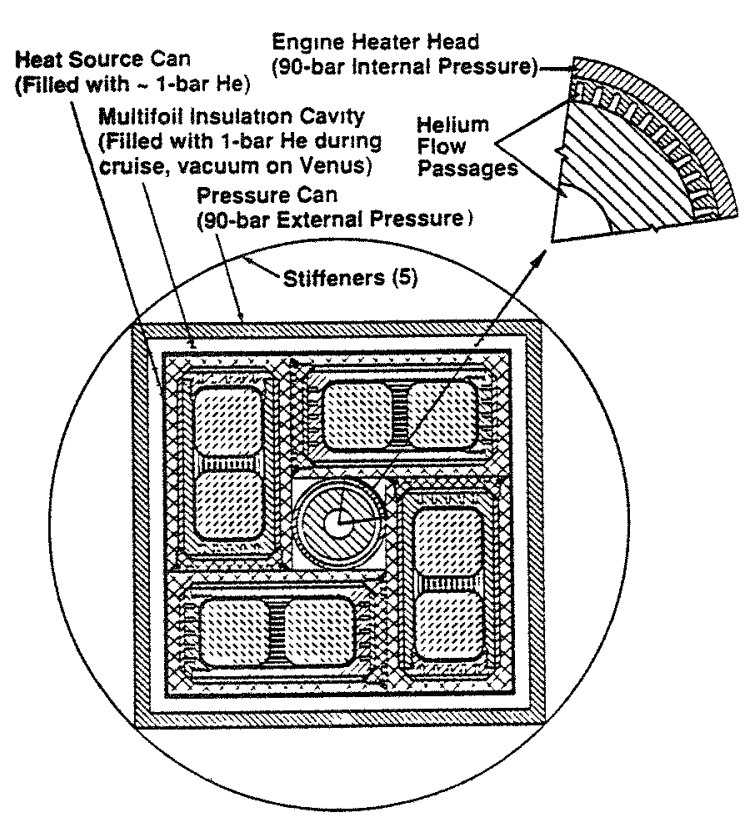

Fig.6 Integration of Heat Source with Engine Heater Head results in a pressure rise of only 0.06 bar per year or 4 torr per month. If the fuel chamber and electronics bay are initially charged with 1 bar of helium, the effect of the additional helium pressure would be insignificant.

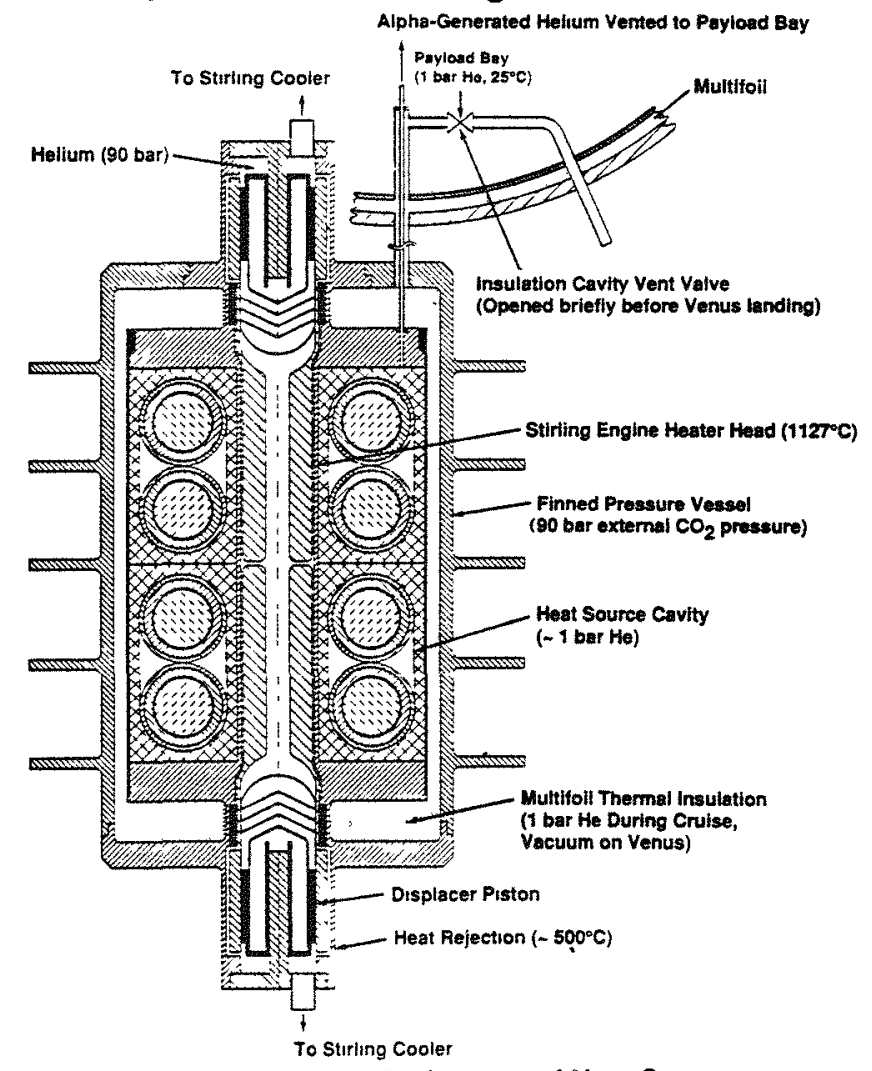

Fig.7 Stirling Engine with Integrated Heat Source 
An additional advantage of always having -1 bar of helium in the heat source chamber is that it significantly reduces the temperature drop between the heat source surface and the engine's heater head, and the internal temperature drops within the heat source modules. This helps reduce the operating temperature of the fuel pellets' iridium clads, which is important because excessive iridium temperatures could lead to grain growth and embrittlement in case of inadvertent Earth reentry.

The second part of the gas management scheme depicted in Figure 7 relates to the requirement for evacuating the heat source's and the electronics bay's insulation chambers, to activate the multifoil thermal insulation. As shown, those two chambers are connected through a tube that surrounds the previously mentioned alpha-helium capillary. A valve placed in a side arm of that outer tube vents the initial helium charge from both insulation chambers to space vacuum, prior to entry into the Venus atmosphere. After evacuation, the valve must close to prevent entry of the high-pressure Venusian atmosphere into the insulation chamber

The helium evacuation valve could have been attached to the outer tube that connects the engine pressure vessel to the payload bay pressure vessel. But that would have required the valve to operate at the Venusian temperature of $500^{\circ} \mathrm{C}$. To avoid that requirement, the evacuation valve has instead been located inside the lowtemperature $\left(25^{\circ} \mathrm{C}\right)$ electronics bay for enhanced reliability. Reliability can be further enhanced by using a matrix of $2 \times 2$ valves.

The heat source's square pressure can must be able to withstand an external pressure of 90 bars at its operating temperature of $500^{\circ} \mathrm{C}$. To confirm that it can do so, a NASTRAN structural analysis was carried out, with the results displayed in Figure 8. For a titanium wall thickness of $0.63 \mathrm{~cm}$, lid thickness of $1.27 \mathrm{~cm}$, and stiffener thickness of $0.50 \mathrm{~cm}$, the iridium pressure can have a maximum deformation of $0.18 \mathrm{~cm}$ and a von Mises stress of $50 \mathrm{ksi}$, well within acceptable limits.

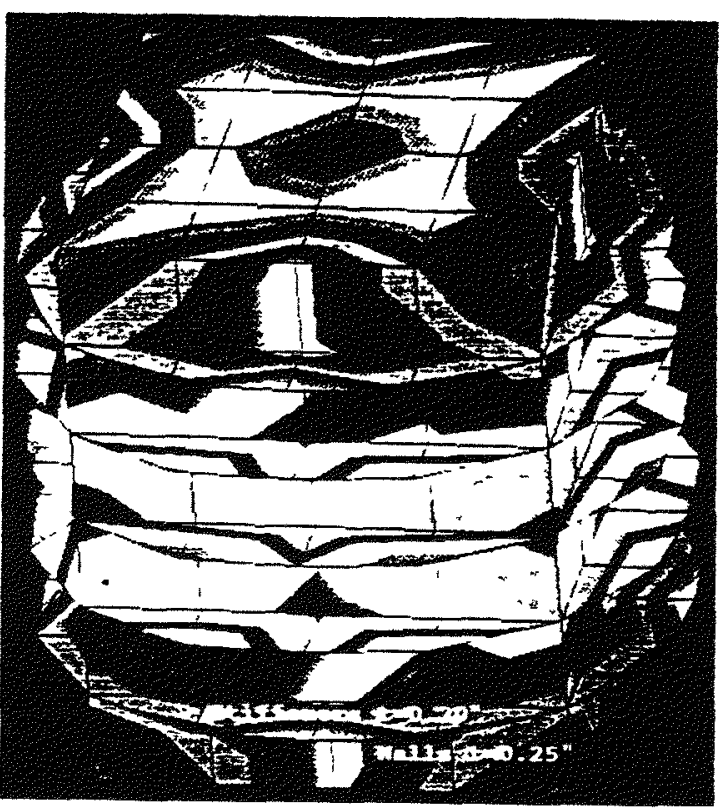

Fig.8 Stresses in Pressure Can

Next, thermal analyses of the lander were carried out to determine the critical heat source temperature while stowed during cruise and after deployment on Venus. The assumed stowed configuration is depicted in Figure 9.

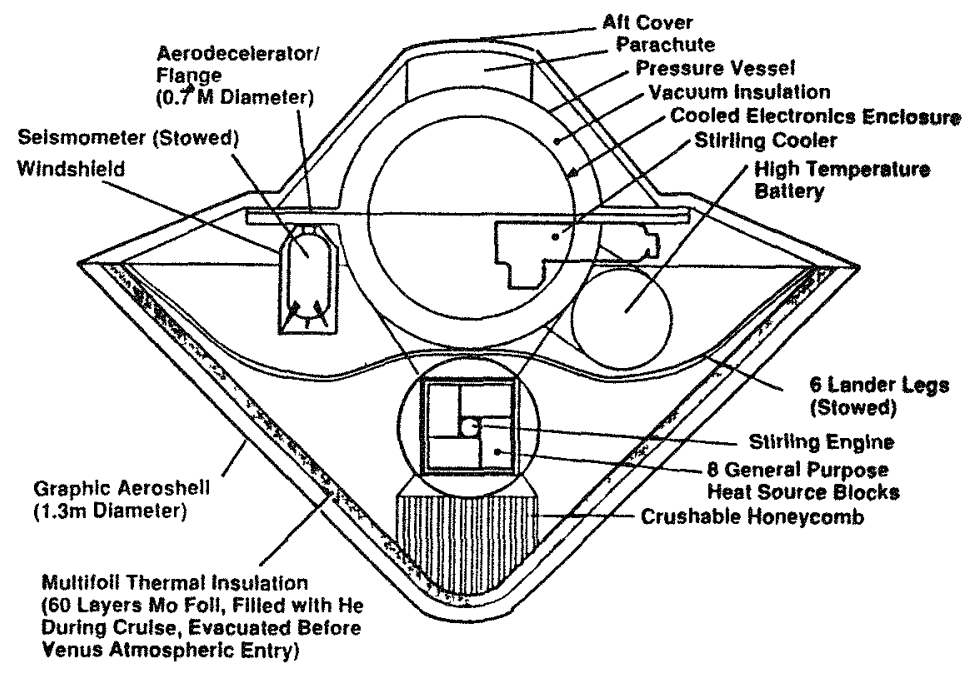

Fig.9 Entry Capsule and Lander

As shown, the spacecraft is protected by a graphite aeroshell whose inside is lined with multifoil thermal insulation to prevent overheating the payload during the spacecraft's subsequent entry into the dense Venusian atmosphere. During cruise, the insulation package is flooded with helium to allow the isotope decay heat to leave the spacecraft. 
Figure 10 shows the spacecraft after its landing on Venus, with its support legs and seismometer deployed. The figure shows an externally mounted NaS battery, 'but JPL subsequently decided to employ a conventional battery on the inside of the refrigerated payload bay.

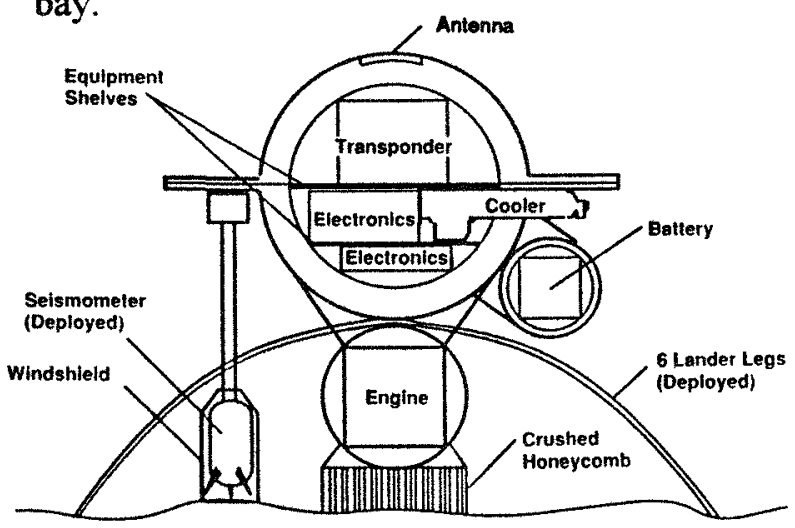

Fig.10 Lander System on Surface

The key results of the thermal analyses are displayed in Figures 11, 12, and 13. Figure 11 shows the temperatures during cruise, and Figure 12 shows the temperatures on Venus.

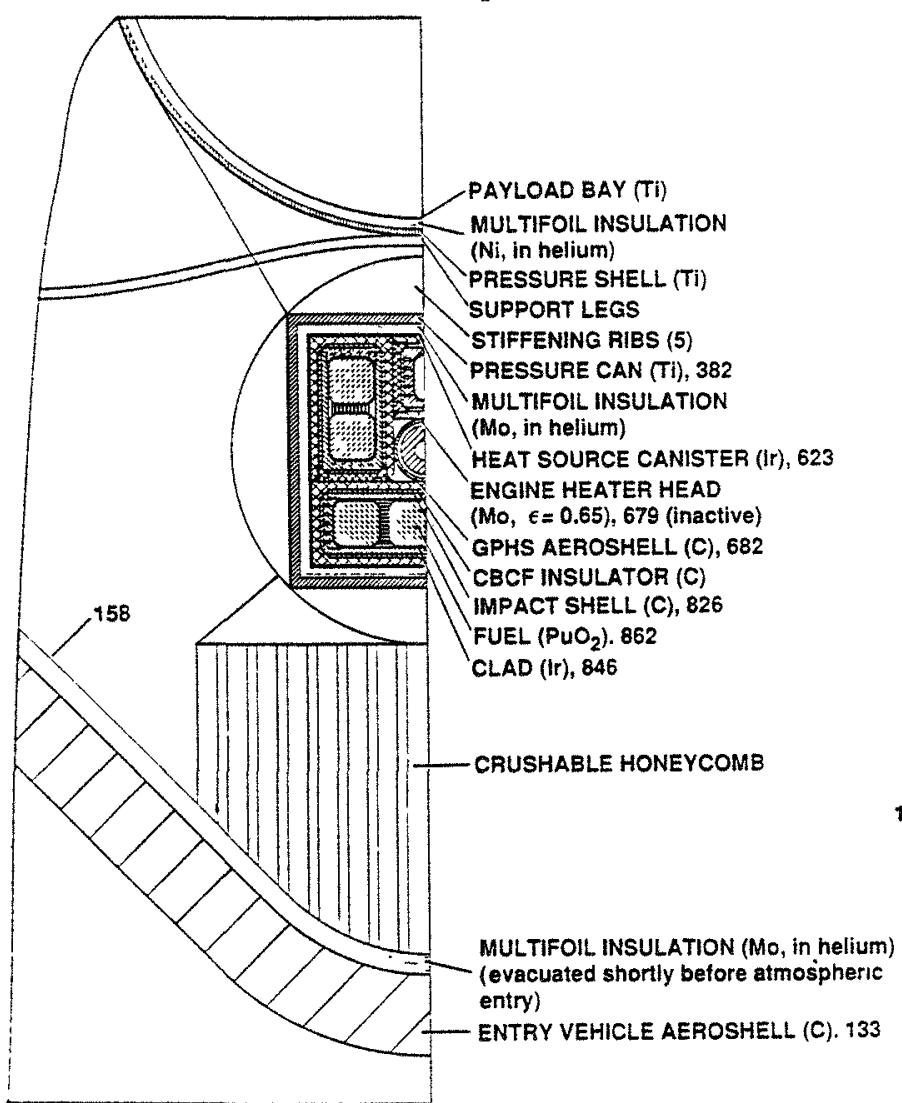

Fig.11 Temperature Distribution $\left({ }^{\circ} \mathrm{C}\right)$ During Cruise (Before Separation from Carrier)

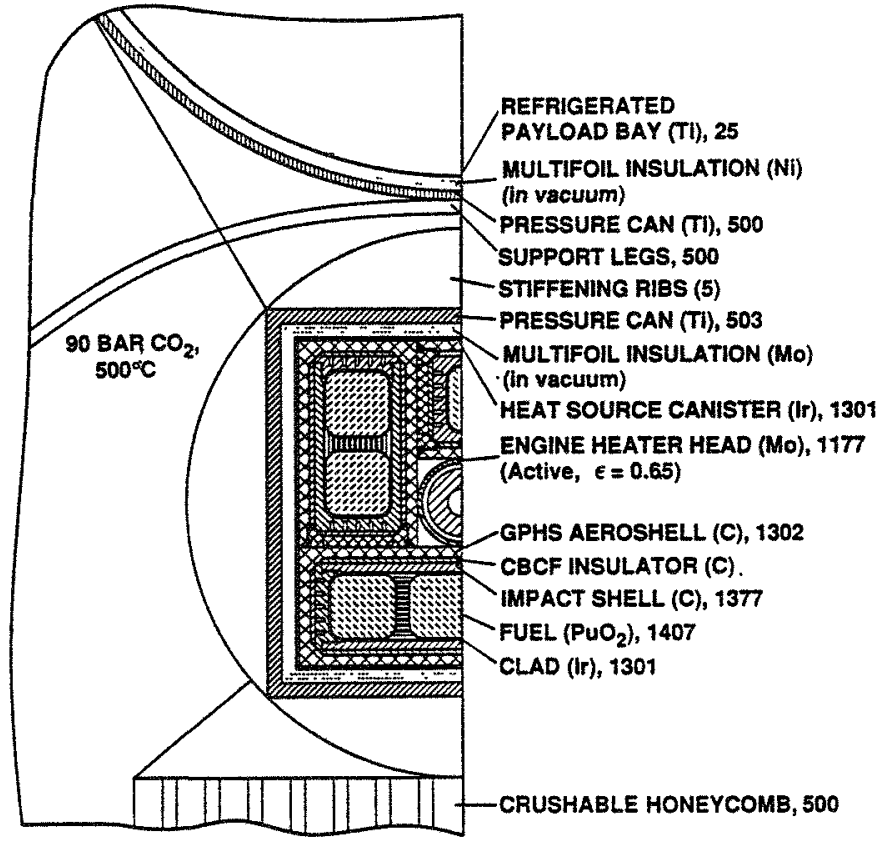

Fig.12 Temperature Distribution $\left({ }^{\circ} \mathrm{C}\right)$ on Venus

Detailed operating temperatures of the heat source in the two environments are compared in Figure 13. The left half of the figure represents the condition during cruise in a vacuum environment, with the engine not operating and the thermal insulation chamber flooded with helium. The figure's right half represents operation in the Venusian environment, with the engine running and the insulation chamber evacuated.

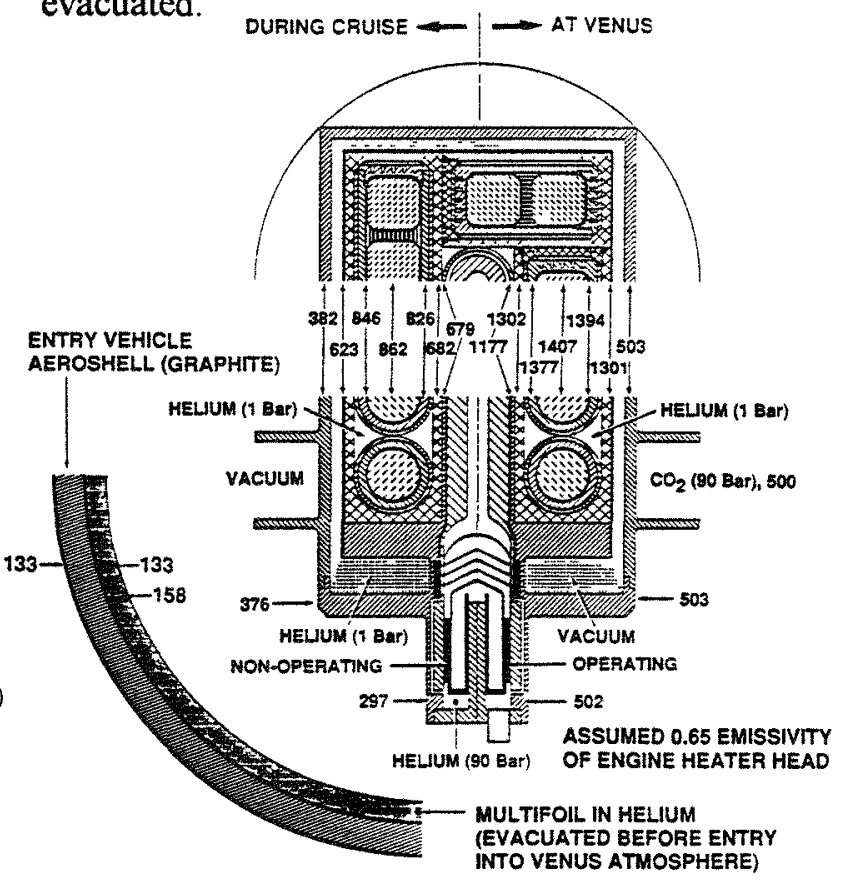

Fig.13 Heat Source Operating Temperatures $\left(C^{\circ}\right)$ 
The figure shows that the outer pressure can operates at $376^{\circ} \mathrm{C}$ during cruise and at $503^{\circ} \mathrm{C}$ on Venus. The analysis, assuming 60 foil layers, showed that with the engine running, only $3.6 \%$ of the generated heat is lost through the multifoil insulation. This heat loss can be further reduced by using 120 instead of 60 foils.

Since the heat source's graphitic components can tolerate extremely high temperatures, our principal interest is in the temperature of the iridium clad, since long-term operation at high clad temperatures could lead to excessive grain growth and consequent clad embrittlement [2]. As shown in Figure 13, the predicted clad temperature is $838^{\circ} \mathrm{C}$ during cruise and $1329^{\circ}$ $\mathrm{C}$ on Venus. The cruise temperature is low enough to make grain growth insignificant, but the clad temperature on Venus is high enough to cause some grain growth. However, this is acceptable for two reasons: First, the $1329^{\circ} \mathrm{C}$ temperature is still within the accepted limit for RTG heat sources. And second, embrittlement is of concern primarily for safety reasons, in case of launch aborts and returns to Earth. It is of much less concern when there is no longer any possibility of returning to Earth. In the present case, grain growth would not start until arrival at Venus. Therefore, the predicted operating temperature is acceptable from both a safety and a functional viewpoint.
Table 1 presents a mass breakdown of the isotope-powered refrigeration system and of the payload bay (without the payload). As shown, their total mass is $65.8 \mathrm{~kg}$.

Figure 14 presents an energy balance summarizing the thermal $(\mathrm{t})$, mechanical $(\mathrm{m})$, and electrical (e) energy flow rates in the system.

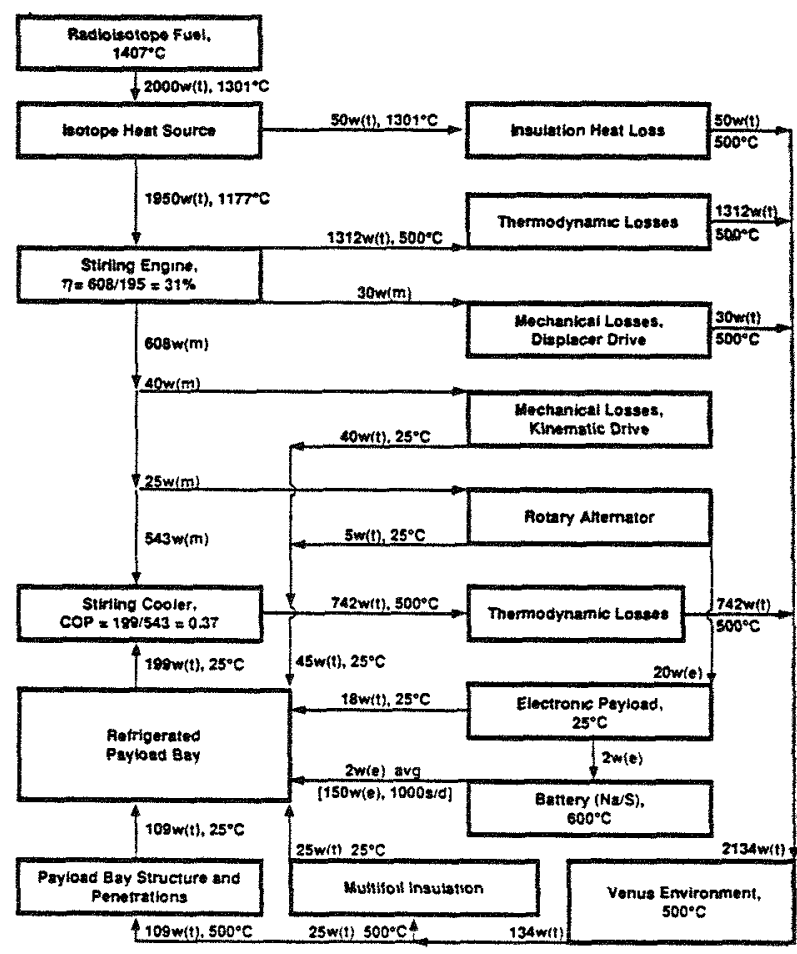

Fig.14 Energy Flow Summary

Table 1 Mass of Payload Bay and Isolope-Powered Refrigeration System (Excluding Payload)

\begin{tabular}{|l|r|}
\hline Radioisotope Heat Source (8 GPHS) & $\mathrm{kg}$ \\
Heat Source Canister (Ir) & 4.0 \\
Multifoil Thermal Insulation (Mo, 0.0003", 60 layer) & 1.5 \\
Heat Source Pressure Shell (Ti, 0.25" wall, five 0.20" stiffeners) & 9.6 \\
\cline { 2 - 2 } & 26.7 \\
\hline Stirling Engine (Mo) & 10.0 \\
Pneumatic Coupling (Ti) & 0.5 \\
Stirling Cooler \& Alternator & 9.1 \\
Heat Pipes and Radiators & 7.0 \\
\hline Payload Bay Canister (Ti, 15" dia., 0.025" wall, 25 $\left.{ }^{\circ} \mathrm{C}\right)$ & 26.6 \\
\hline Multifoil Thermal Insulation (Ni) & 1.3 \\
Payload Bay Pressure Shell (Ti, 0.165" wall, 500 & 1.8 \\
& 9.4 \\
\hline & 12.5 \\
\hline \multicolumn{1}{c}{ TOTAL } & 65.8 \\
\hline
\end{tabular}


Finally, Figure 15 summarizes the design layout, and overall dimensions of the Stirling engine, cooler, and refrigerated payload bay, and a functional block diagram of the payload.

\section{Acknowledgments}

The author is pleased to reiterate the role of JPL personnel (Stefan, Saunders, Nock, et. al.) in developing the basic mission concept and the role of LeRC (Dudenhoefer) and MTI (Dochat, Vitale, Dhar) in designing and analyzing the Stirling engine and refrigerator. He also wishes to thank his Fairchild colleagues (Sankarankandath, Noravian, Or) for their contributions to this study, and DOE's Office of Special Applications for its guidance and support.

\section{References}

[1] Stofan, Ellen R. and R. Stephen Saunders (1992) "Venus Interior Structure Mission (VISM)" presented at the Discovery Missions Workshop, Sept. $9,1992$.

[2] Schock, A. (1980) "Design Evolution and Verification of the General-Purpose Heat Source," \#809203 in Proc. of 15th Intersociety Energy Conversion Engineering Conference, held in Seattle, WA.

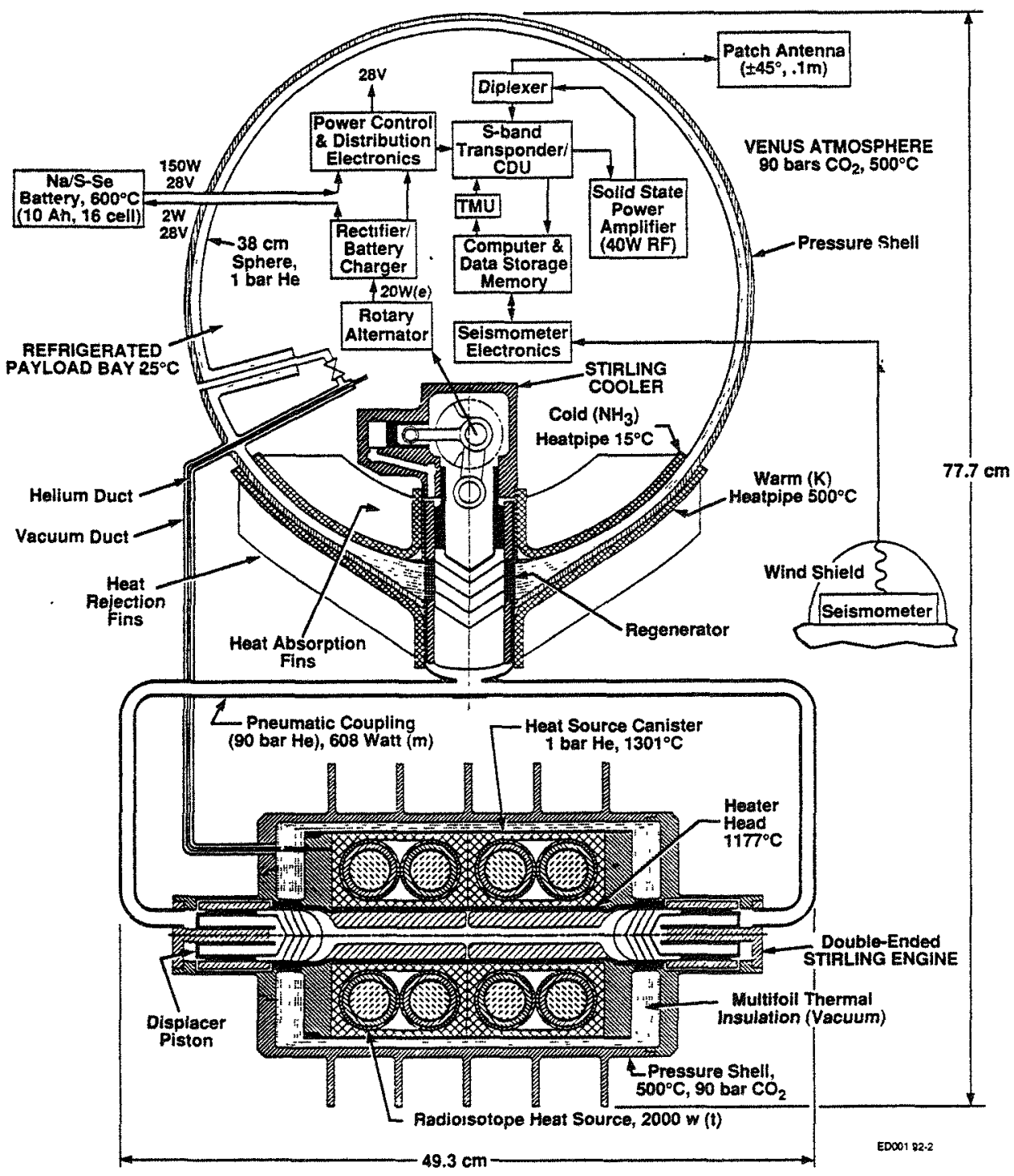

Fig.15 Venus Lander: Functional Block Diagram and Payload Refrigeration System Design 